\title{
EL ORIGEN DE LA VIDA
}

Gladys León Sacedo, MD.*

A propósito del libro "La Biología del Futuro, ¿Qué es la Vida? 50 años después", escrito por el connotado biólogo Stephen Jay Gould fallecido recientemente y de la clase dictada por el filósofo Carlos Maldonado en su cátedra de fundamentación, en la maestría en bioética de la Universidad El Bosque, Gladys.León Salcedo ${ }^{1}$ realizó el trabajo que se pública.

Abordemos los planteamientos de Schrodinger desde otra óptica, para buscar fenómenos tan apasionantes como la transformación de la energía en materia y la materia en vida.

Al principio de los tiempos, el universo oscuro, viscoso y opaco, se va aclarando a medida que la radiación se transforma en materia y gracias a este fenómeno, se enfría y los gases que lo hacen opaco y viscoso van desapareciendo. Emerge la materia y con ella la luminosidad, la perspectiva, la visibilidad.

Los átomos ligeros (gases) van constituyendo átomos pesados que hacen posible el surgimiento de la vida y los procesos incesantes de transformación de energía llevarán tres mil millones de años más tarde, a la transformación de la materia en vida. "Somos energía cósmica transformada".

* Jefe de la Oficina Jurídica de la Sociedad de Cirugia de Bogotá, Hospital de San José y Asesora de la Fundaciòn Universitaria de Ciencias de la Salud.

I Stephen, Jay Gould. Qué es la vida? como problema histórico. En: La Biología del futuro. Qué es la vida cincuenta años después, Tusquets Editores S.A (Metatemas), Barcelona 1999.pág 4I.

2 (Cualquier repetición de la película de la vida a través de la lotería cámbrica habría arrojado un conjunto enteramente distinto de linajes supervivientes; en este sentido, cualquier forma de vida presente debe su existencia a la fortuna). Las preguntas que se refieren a nosotros de manera más genuina y profunda, aun cuando hayan sido convencionalmente enmarcadas como cuestiones sobre esencialidades temporales, han de responderse en términos de contingencia. Diferencias mínimas en el dominio de la contingencia histórica, aparentemente intrascendentes para cualquier observador coyuntural se traducen en resultados absolutamente dispares que alteran de manera fundamental la cuestión de qué es la vida.... La contingencia no es solo el dominio de lo trivial. Es más, el tema de la contingencia es fractal, e
Es por tanto, la vida un nivel de orden superior frente a la energía y a la materia; con variaciones maravillosas en sus niveles, pero con los mismos componentes. La vida es el máximo grado de transparencia del universo con respecto a sí mismo y esto es todo un tratado para la Bioética.

¿Qué es y cómo surge la vida? No lo sabemos: "las verdades obvias pueden resultar sumamente difíciles de definir". ${ }^{2}$ Sabemos que no hay soluciones de continuidad sino procesos emergentes, en los cuales la contingencia ocupa un papel muy importante. "Somos entidades contingentes y no inevitabilidades predecibles". 3

Partiendo de Schrodinger, la entropía como cantidad física medible y como "concepto estadístico de orden y desorden" tiene significación en el análisis del comportamiento de los seres vivos, siendo el estado de máximo equilibrio termodinámico, el de máxima entropía. Mientras más se aleja un proceso del nivel de máxima entropía es más vital e intenso. En el alejamiento de la entropía positiva emerge lo contingente: "la vida se alimenta de entropía negativa". ${ }^{4}$ Más tarde el mismo Schrodinger consignaría su inconformidad con la expresión "entropía negativa" argumen-

impregna todas las escalas de la historia de la vida desde los cataclismos biosféricos hasta las particularidades de los linajes concretos. En : Stephen, Jay Gould Qué es la vida? como problema Histórico. En: La Biología del futuro. Qué es la vida cincuenta años después, Tusquets Editores S.A (Metatemas), Barcelona 1999.págs 58-59.

3 Todo proceso, suceso o acontecimiento-llámese como se quieraen una palabra todo lo que pasa en la naturaleza, significa un aumento de la entropía de aquella parte del mundo donde ocurre. Por lo tanto, un organismo vivo aumentará continuamente su entropía o, también puede decirse, produce entropía positiva $-\mathrm{y}$ por ello tiende a aproximarse al peligroso estado de entropía máxima que es la muerte-. Sólo puede mantenerse lejos de ella, es decir, vivo, extrayendo continuamente entropía negativa de su medio ambiente, lo cual es algo muy positivo, como un seguimiento de veremos. De lo que un organismo se alimenta es de entropía negativa. $O$, para expresarlo menos paradójicamente, el punto esencial del metabolismo es aquél en que el organismo consigue librarse a sí mismo de toda la entropía que no puede dejar de producir mientras está vivo. En: Erwin Schrôdinger, Orden, desorden y entropía. En: Qué es la vida?, Tusquets Editores S.A (Metatemas), Barcelona. págs II0-II2. 
tando que la ha utilizado en lugar de la expresión "energía libre" para hacer más sencillo el tema a los legos en la materia.

La entropía que puede ser gravitacional, química, térmica etc. explica fenómenos tan interesantes como la atracción de los cuerpos. La entropía gravitacional guarda fuertes lazos con el origen de los sistemas planetarios, las galaxias y las estrellas.

Cincuenta años más tarde del escrito de Schrodinger, Kauffman interrogándose sobre las razones de aquel, cuando planteaba la necesidad de un sólido aperiódico para la emergencia de la vida o su evolución, responde negativamente: la emergencia de la vida o su evolución no requieren de "portadores estables de información heredable", el origen de la vida es una transición de fase que ilustra cómo puede surgir el orden del desorden.

La materia es una interfase como también lo es el ser humano. Somos energía sedimentada y autosostenida y los procesos incesantes de transformación de energía han llevado a la vida. Esta se mantiene por su capacidad de recibir más energía de la que pierde.

Somos más que materia, somos vida favorecida por factores como el tiempo y la expansión del universo, por estructuras, patrones, comportamientos y proliferación de formas que permiten la vida. Pangea se rompe, los procesos de glaciación y demás fenómenos per- miten la especiación. Supuesta la vida, el universo no tiene reverso.

Que la vida es posible gracias a que vivimos en un universo en expansión significa que los grados de vida se van haciendo posibles en sistemas más inestables y alejados del equilibrio. Surgen dimensiones de una complejidad cada vez superior, así como accedemos a grados de libertad cada vez mayores.

La información sobre el universo aún es muy pobre, existen ligeros datos que brindan la química, la física, y otras ciencias aún incapaces de explicar los fenómenos espacio - temporales que tienen lugar dentro de los límites espaciales de un organismo. Laingeniería genética representa un avance del conocimiento, un avance de la materia sobre sí misma. Se pensó que la biología daba una gran información sobre la vida, aunque ésta apenas tiene algunas generalizaciones sobre los seres vivos pero carece de una teoría de la vida.

La Bioética tiene por fin dilucidar un tipo de vida al que le va el ethos. Dado que la selección natural no opera y la que está operando es la selección cultural, el problema es pensar si es posible que los seres tomen el control de su vida en sus propias manos. (5) El futuro del universo no se decidirá a nivel de la ciencia. Aquel se decide a través de la reflexión sobre la ciencia. El futuro de la humanidad está en comportamientos y actitudes compatibles con la Bioética.

\footnotetext{
4 La humanidad no es como un organismo pluricelular en el que cada célula se debe por ley genética al bien común de la colectividad celular. La información cultural no es heredada por el individuo, como tampoco lo es la conducta socialmente aceptable. Después de milenios de evolución cultural, la gente sigue haciéndose la guerra, y con la misma crueldad de siempre. Nos engañamos a nosotros mismos si creemos que la conducta socialmente aceptable es algo natural y que la conducta asocial, por el contrario, es patológica. Esto es la norma sólo en el sentido del término latino original, que significa ley o regulación. Más adelante se lee. Las ideologías no pueden reemplazar la razón. Nada cambiará si no basamos nuestras decisiones en la razón, aceptando la humanidad como un imperativo moral. El futuro del género humano no se decidirá al nivel genético. Necesitamos un sistema ético que sea vinculante para todo el mundo. En : Stephen, Jay Gould Qué es la vida? como problema Histórico. En: La Biología del futuro. Que es la vida cincuenta años después, Tusquets Editores S.A (Metatemas), Barcelona 1999.págs 39-40.
} 